\title{
Community Resilience in Southern
}

Appalachia: A Theoretical Framework and Three Case Studies

\section{Jordan W. Smith, Roger L. Moore, Dorothy H. Anderson \& Christos Siderelis}

\section{Human Ecology}

An Interdisciplinary Journal

ISSN 0300-7839

Volume 40

Number 3

Hum Ecol (2012) 40:341-353

DOI 10.1007/s10745-012-9470-y

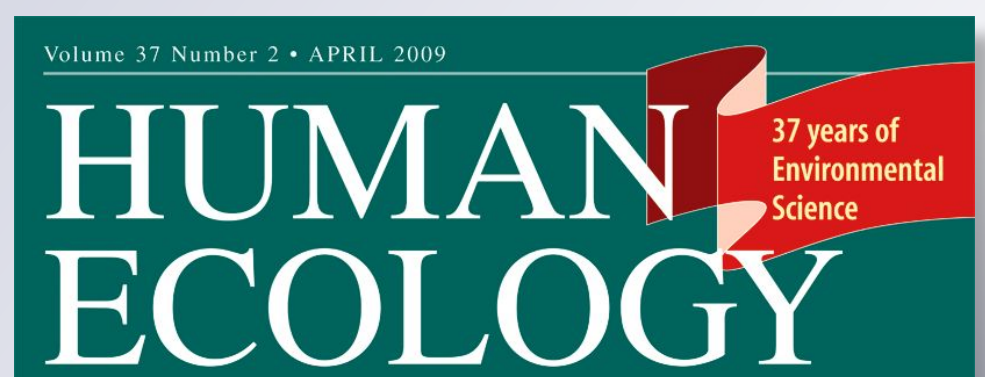

AN INTERDISCIPLINARY JOURNAL

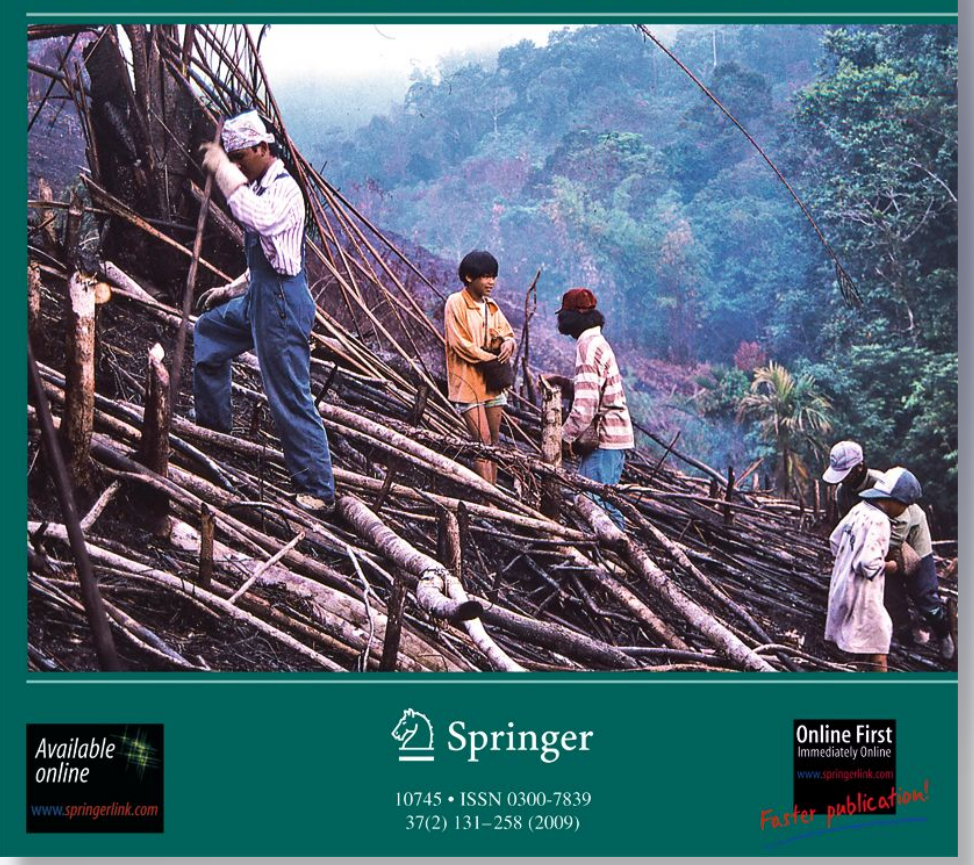

囪 Springer 
Your article is protected by copyright and all rights are held exclusively by Springer Science+Business Media, LLC. This e-offprint is for personal use only and shall not be selfarchived in electronic repositories. If you wish to self-archive your work, please use the accepted author's version for posting to your own website or your institution's repository. You may further deposit the accepted author's version on a funder's repository at a funder's request, provided it is not made publicly available until 12 months after publication. 


\title{
Community Resilience in Southern Appalachia: A Theoretical Framework and Three Case Studies
}

\author{
Jordan W. Smith • Roger L. Moore • \\ Dorothy H. Anderson • Christos Siderelis
}

Published online: 1 April 2012

(C) Springer Science+Business Media, LLC 2012

\begin{abstract}
A fundamental assumption in nearly all research on social adaptation to environmental change is that there is a concomitant and inverse relationship between human communities' dependence upon particular natural resources affected by environmental change and those communities or societies' resilience to disturbances. However, recent theoretical and empirical developments suggest resilience is a dynamic social process determined, in part, by the ability of communities to act collectively and solve common problems. The interactional approach to community is utilized to develop a framework whereby various patterns of social interaction define the process of social resilience. Data come from multiple mixed methods case studies of forest dependent communities within Southern Appalachia. The findings reveal varied processes of social resilience can occur in communities with similar levels of resource dependence; a community's composition of internal social ties and their cross-scale linkages to external agencies and organizations define these processes.
\end{abstract}

Keywords Resource dependence · Social capital ·

Adaptation

\section{Introduction}

Human communities, societies and civilizations have been adapting to changing environmental conditions since long before written histories were recorded (McIntosh et al. 2000).

J. W. Smith $(\bowtie)$

Department of Forestry and Natural Resources, Purdue University,

West Lafayette, IN, USA

e-mail: smit1547@purdue.edu

R. L. Moore · D. H. Anderson · C. Siderelis

Department of Parks, Recreation and Tourism Management,

North Carolina State University,

Raleigh, NC, USA
However, current global trends spurred by anthropogenic causes such as increases in mean annual atmospheric temperatures, rising sea levels and more frequent and severe natural disasters, have raised serious concerns about the capabilities of modern communities, societies and civilizations to successfully adapt (National Academy of Sciences 2010). As a result, a burgeoning body of scientific research is being devoted to understanding the complex relationship between climate change impacts and social responses.

A fundamental assumption evident in nearly all research on social adaptation to environmental change is that there is a concomitant and inverse relationship between human communities' or societies' dependence upon particular natural resources affected by environmental change and those communities or societies' resilience to such disturbances. Dependence on a narrow range of natural resources increases social vulnerability as disturbances affecting resource stability can cause severe variability in the production of socio-economic benefits (Adger 2000). In this paper, we examine communities' dependence upon natural resources to determine if, in fact, resource dependence negatively affects the socio-economic stability of those communities.

While previous research suggests natural resource dependence is a major determinant of social resilience (Adger 2000; Machlis and Force 1988), recent theoretical and empirical developments suggest resilience is a dynamic social process determined, in part, by the ability of communities to act collectively and solve common problems (Adger 2003; Folke et al. 2005). Given this, we also analyze how specific patterns of social interaction can influence a community's ability to adapt to changing environmental conditions. Specifically, we utilize existing social capital theory and the interactional approach to community to develop a theoretical framework for better understanding the role social interaction plays in community resilience. 
Fundamentally, this paper has two primary objectives. The first objective is to examine how the dependence of human communities upon the availability and production of natural resources can affect the long-term stability of those communities. The second objective is to explore resilience as a process facilitated through the presence of specific types and patterns of social interaction. Achieving these objectives contributes to the development of a more integrative theoretical framework. This integrated framework is useful as both a social scientific tool that can be utilized to further the understanding of how human communities have, and are capable of, adapting to increasingly variable environmental conditions. The framework can also inform resource management and social governance processes by illustrating how specific social outcomes, such as economic stability, can be achieved through the multiple pathways linking various natural resource dependencies and specific patterns of social interaction.

\section{Theoretical Framework}

\section{Social Resilience}

As scientific and public concern over the biophysical impacts of climate change have increased over the past several decades (Aspinall 2010) so too has the social scientific endeavor of understanding how human individuals, communities, and societies have, or are capable of, adapting to changing environmental conditions. A large amount of scientific evidence makes clear that many ecological systems are transitioning into dramatically different states defined by more variability, complexity and uncertainty than at any previous point in history (National Research Council 2010a, b). Solely mitigating the anthropogenic drivers of climate change is not a sustainable solution; rather, individuals, communities, and societies need to develop their capacities to adapt to unpredictable environmental futures.

Resilience theory, originating within the field of systems ecology, has emerged as the dominant scientific paradigm through which both biophysical and social adaptations to climate change can be understood. ${ }^{1}$ Resilience theory is grounded in the concept that all social and ecological systems are not stable (May 1977). Rather, these systems can exist within multiple states of self-organization, within which, the relationships between system properties are relatively persistent and capable of absorbing disturbances from external sources (Holling 1973). A social or ecological system's resilience is defined by the magnitude of shock the system can absorb and remain within a given state, the

\footnotetext{
${ }^{1}$ However, the theory's applicability to social systems has been called into question (Davidson 2010; Wilbanks and Kates 2010).
}

degree to which the system is capable of self-organization, and the degree to which the system can build capacity for learning and adaptation (Folke et al. 2002).

The ability of a social or ecological system to remain within a particular organizational state, its resilience, is a function of interactions between system properties within and across multiple scales (Holling and Gunderson 2002). In a human context, resilience, like any other social phenomenon, is inherently a social process guided by specific types and patterns of social interaction. Despite this fact, the growing body of literature concerned with social resilience has yet to fully describe and analyze how specific types and patterns of interaction affect, either by helping or hindering, communities' ability to adapt to external stressors. An interactional approach to community provides the necessary basis from which these patterns of social interaction can be analyzed.

\section{Interactional Approach}

The interactional approach to community suggests community is defined by three elements: i) a locality; ii) a local society; and iii) a process of locally oriented collective actions (Wilkinson 1999). The third element—processes of locally oriented collective action - is a central determinant of a community's resilience. According to the interactional approach, processes of locally oriented collective action must benefit the entire population of a locality for them to be truly actions of the community, as opposed to actions that just occur within the community (Wilkinson 1999, 32-33). Locally oriented collective actions (community actions), are therefore facilitated by community members' ability, through their patterns of interaction, to address collective problems. The process of resilience is defined by unique patterns of interaction within a social system; these processes "involve the interdependence of agents through their relationships with each other, with the institutions in which they reside, and with the resource base upon which they depend (Adger 2003, 388).

A large body of sociological theory suggests specific patterns of social interaction can define how a community is able to respond to collective problems. For example, Durkheim (1933) originally suggested that social solidarity (i.e., the persistence of community) required high levels of social interaction, what he referred to as moral (or dynamic) density. Relevantly, Durkheim also suggested moral density was a direct product of material (or physical) density; thus suggesting rural areas were less capable than their urban counterparts of responding to collective problems. Both Hawley (1950) and Castells (1977) present similar arguments suggesting rural areas are less resilient given that their lower population densities inhibit opportunities to interact. This line of sociological inquiry presents a foundation for understanding 
the relationships between specific patterns of social interaction in terms of a community's ability to maintain its organization in the face of change. Specifically, this early research laid the groundwork for a more formalized framework of social interaction defined by the concept of social capital.

\section{Social Capital}

Social capital is a central component of resilience as it provides a well-developed analytical framework that focuses on the resources available to individuals and communities, provided to them via their social ties, which can be drawn upon to address collective problems. The concept is most generally defined as the "information, trust, and norms of reciprocity inhering in one's social networks" (Woolcock 1998, 153). The work of social theorists Bourdieu (1986) and Coleman (1988, 1990) conceptualize social capital as a collective possession of those individuals connected by social ties. Explicitly stated, "social capital is the aggregate of the actual or potential resources which are linked to possession of a durable network of more or less institutionalized relationships of mutual acquaintance and recognition — or in other words, to membership in a group" (1986, 248).

The central thesis tying social capital to community resilience is that social capital defines both the material resources available within a community's social system and the ability of those resources to be mobilized, and subsequently utilized, within the network. The relative "strength" of the ties connecting individuals within the community determines if and how resources can flow throughout the community. Strong, or bonding, ties are relations between family members, friends, and neighbors in closed, tightly connected networks (Gittell and Vidal 1988). Bonding ties create dense network structures and strong but localized feelings of trust. Conversely, weak, or bridging, ties are relations between individuals or communities across distinct social networks. Bridging ties give access to resources and opportunities that exist in one network to members of another network (Granovetter 1973).

A community is not defined solely by either bonding or bridging ties. Rather, all communities' social networks contain an aggregate amount of both types. When conceptualized together, the aggregate level of each type of tie within a community can be utilized to define specific patterns of social interaction within that community. Figure 1, Panel A illustrates this community social capital typology. Communities with high stocks of both bonding and bridging social capital have a high degree of inclusion, as there are numerous horizontal and vertical ties within the community. Communities with high stocks of bonding capital yet low stocks of bridging capital are characterized by a high degree of internal factionalism and conflict. Communities with low bonding yet high bridging ties are defined by dependence and clientelism. Examples frequently cited within the rural and natural resource literatures include factory towns in which community development is controlled by a small business elite (e.g., Schulman and Anderson 1999). Finally, communities with low stocks of both bonding and bridging social capital are characterized by apathy and extreme individualism (Flora and Flora 2003).

\section{Mixed Methods Multiple Case Study Methodology}

To date, a large proportion of natural resource social science, particularly research grounded in sociological frameworks, has involved the use of case studies. The prevalent use of case studies by natural resource sociologists is most likely attributable to i) the emphasis placed upon linkages between localized resource conditions and patterns of community organization and change; ii) the theoretical roots of the field within human ecology; and iii) the field's primary focus of solving local land-use issues as opposed to developing more generalizable theories (Field et al. 2002). This research follows suit and employs a multiple-case study design. A multiple-case design, following replication within each case, enables a study's results to be more robust to unique contextual factors that may influence results (Herriott and Firestone 1983). The external validity of study findings are also bolstered through the use of replicated case studies (Yin 2009). Concurrently, the findings from multiple-case designs can yield greater analytic generalization, in which previously developed theories can be utilized as a template with which to compare the results of each study and build more generalizable theoretical frameworks (Gomm et al. 2000).

The individual cases within this study are three counties (Haywood, Macon, and Mitchell) located in western North Carolina, USA. Cases were selected based upon three criteria: i) the county had to have been economically dependent upon natural resource based industries in the past (defined as $>10 \%$ employment in either farming, forestry, fishing, hunting or mining); ii) the county had to be predominantly forested, with the primary population center located adjacent to publically managed forests, and iii) the counties had to be as geographically and socio-demographically similar as possible. This logic underlying the selection of similar cases enabled us to predict similar results (a literal replication) based upon our guiding theoretical propositions while minimizing potentially confounding contextual influences (Yin 2009).

\section{Data Collection and Analysis}

Within each case community, we utilized mixed methods research techniques enabling the study's capacity to generate 
A

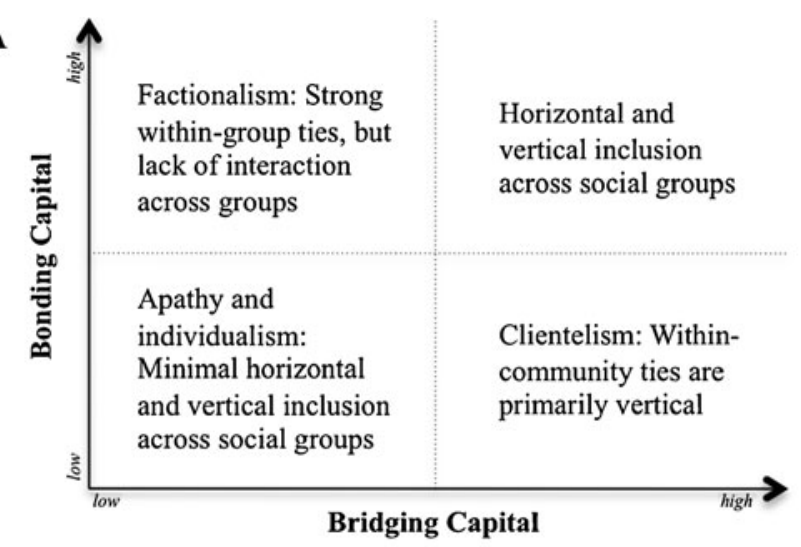

NATURAL RESOURCE DEPENDENCE

B

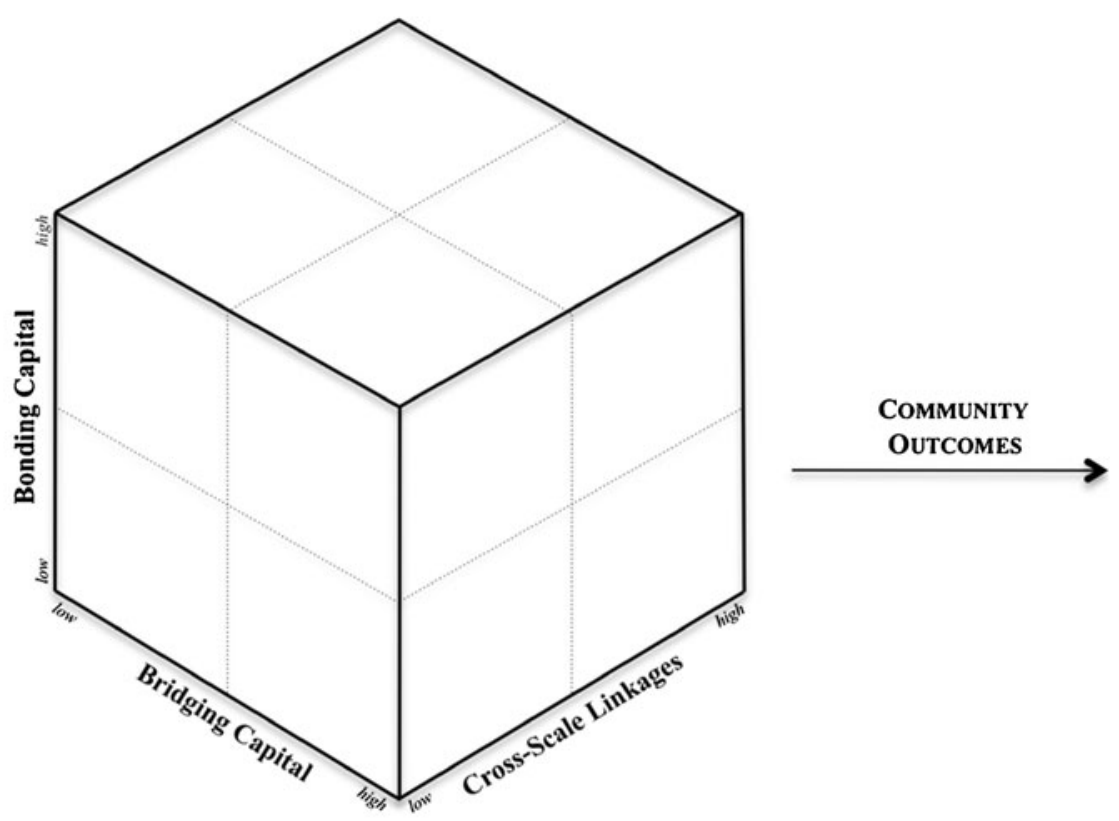

\section{Social CaPital}

Fig. 1 Social capital and the multiple pathways of resilience

more analytically and theoretically generalizable results. Specifically, we collected secondary data on the historical trends of socio-economic stability, economic natural resource dependence, and social capital for each county. Collection and analysis of historical data provides two benefits. First, it enables us to extend the temporal scope of the analysis of the connections between resource dependence, social capital, and social resilience. Collection and analysis of secondary data allows us to investigate socio-economic resilience across time; this is a critical component of the resilience concept that can easily go unobserved in cross-sectional research. Second, it provides further support for our case-selection logic and hypothesis development by enabling us to illustrate and analyze similar paths of social-economic resilience. Similar trends in socio-economic stability, resource dependence, and levels of social capital provide stronger support that similar forms of resilience should, hypothetically, be seen across each case.

As a secondary source of data, we also conducted semistructured interviews with key-informants within each of the cases (counties). Collection and analysis of interview data offers two key complimentary benefits to the mixed methods design. First, interviews with local individuals concerning their community's ability to adapt to changing environmental and economic conditions broadens the study's construct validity. Social resilience does not remain defined by an indicator, but rather is expressed through the words of local individuals who have seen and experienced change and adaptation within their communities in the past. Because qualitative research provides findings based on context-specific 
themes, patterns, and relationships, the use of semi-structured interviews provides both breadth and depth to the analysis. The second benefit of collecting and analyzing interview data is that it provides an avenue for the study's findings to be generalized to resilience theory. More detailed and specific accounts of the social resilience processes enable inductive theory formation to occur, enabling the production of more robust and grounded theoretical frameworks (Dey 1999).

Secondary Data Sources and Indices Secondary data were comprised of key indices frequently used to assess resource dependence, social capital and social resilience. Following previous studies of resource dependence (e.g., Freudenburg and Gramling 1994; Nord 1994) the proportion of a county's total employment within a specific natural resource based industry was used to measure natural resource dependence. This measure, while frequently used in rural economic research, has several drawbacks such as the reliance on pre-defined economic sectors and the reliance upon individuals' place of residence (as opposed to place of employment). Despite these limitations, we utilize the proportional employment approach for this study given the availability of longitudinal employment data and drawbacks associated with alternative measures of economic dependence (see Stedman et al. 2007). Longitudinal data for each of the three study counties was obtained from the Bureau of Economic Analysis (BEA). The three industries for which the BEA collects data that can be defined as directly natural resource dependent are i) farming, ii) agricultural services, forestry and fishing, and iii) mining. For each of these industries, the Standard Industrial Classification (SIC) codes, which were used from 1969 to 2000, match the North American Industrial Classification System (NAICS) codes, which have been used since.

Following previous studies attempting to gauge social capital at an aggregate level (Robison and Siles 1999; Rupasingha et al. 2002, 2006), the number of voluntary membership organizations per capita within a county was used to measure social capital. Voluntary membership organizations are non-market organizations including i) business associations, ii) professional membership organizations, iii) labor unions and similar organizations, iv) civic, social and fraternal associations, v) political organizations, and vi) religious organizations. Consistent with previous social capital research, per capita voluntary membership organizations are believed to be a good indicator of the non-market social connections (i.e., social capital) within a defined geographic area. Longitudinal data for each of the three study counties was obtained from the US Department of Labor. Data collected under the SIC codes (SIC86) were available from 1977 to 2000 and data collected under the NAICS codes (NAICS83) were available from 2001 to 2008 .
Following previous research on community resilience (Machlis and Force 1988), the stability of median household incomes was used to gauge social resilience. Median household income data was obtained for the years 1979, 1989, and from 1995 to 2007 from the US Decennial Census and the US Department of Labor. Median household income values for years where data were not available were generated using a linear interpolation method (StataCorp 2009a) where the $x$ variable was the mean annual salary for all employment within the county. ${ }^{2}$ Collectively, the economic dependence, social capital and socio-economic resilience measures were available for a 31year span from 1977 to 2007 . We structured the data in a timeseries format where time increments were defined by each year of data.

Analysis Any quantitative analysis of socio-economic resilience must acknowledge resilience is primarily a measure of stability as opposed to just economic growth as communities or regions may experience relatively long periods of real wage appreciations due to boom cycles, but actually not be resilient to external stressors such as the loss of the resource base upon which those cycles depend (Brown et al. 2005; Smith et al. 2001). Analytically, we addressed this issue through a multivariate time-series regression approach.

We modeled the median household income of a community at time $t$ as a function of its past values and disturbances and a linear combination of both the social capital and resource dependence variables. The structural portion of our model is expressed as

income $_{t}=\beta_{0}+\beta_{1}$ dependence $_{t}+\beta_{2}$ social_capital $_{t}+\mu_{t}$.

To account for the temporal nature of the data, a firstorder autoregressive process was specified (Hamilton 1994; Box et al. 1994). Specifically, we utilized a Prais-Winsten and Cochrane-Orcutt regression estimation (Davidson and MacKinnon 1993) which is preferred when there are concerns about endogenous regressors and the serially correlated residuals which they create. The specification of the firstorder autoregressive process occurs through the structural error term such that

$\mu_{t}=\rho \mu_{t-1}+\varepsilon_{t}$

where $\rho$ is the first-order autocorrelation parameter and $\varepsilon$ is a residual disturbance parameter.

Analytical Assumptions Before specifying the above model, we satisfied several important assumptions about the time

\footnotetext{
${ }^{2}$ This data is publically available from 1977 to 2008 from the US Census Bureau's County Business Patterns datasets.
} 
series data. First, we determined whether the median household income variable contains a unit root or, alternatively, is generated by a stationary process (i.e., their probability distributions are stable over time). The assumption of stationarity is important as it acknowledges that coefficient estimates do not change over time (Wooldridge 2008). We tested for stationarity with an augmented Dickey-Fuller unit-root test on detrended data (Elliott et al. 1996; StataCorp 2009b). The null hypotheses of the Dickey-Fuller unit-root test is that an autoregressive parameter, $\theta$, is equal to 1 , indicating the data has a unit root. The one-sided alternative is that $\theta$ is greater than 1 , indicating the data are generated by a stationary process. The test involves first detrending the data through a generalized least squares estimation process and then comparing an estimated parameter, $t_{\hat{\theta}}$, to a critical value, $c$, from the Dickey-Fuller distribution (Dickey and Fuller 1979). The presence of stationarity in the data indicate the data can be simply regressed over time, as opposed to first differencing them so they become weakly dependent (Wooldridge 2008).

The second assumption addressed prior to specification of the regression model is determining the stability condition of autoregressive parameters included in the model (Wooldridge 2008). Autoregressive processes are weakly dependent given that adjacent terms in time series data are correlated. Correct model specification involves estimating autoregressive parameters up until the point they become independent of the current term. We determine the correct number of autoregressive parameters to be estimated by determining the autocorrelation of terms between time periods (StataCorp 2009c) and setting the number of parameters equal to the number of partial autocorrelations, beginning with lag 1 , within a $95 \%$ confidence interval about the mean. Analysis of autocorrelation of the income variable for all three data sets dictated that only one lag should be included in the estimation process. Given this, we utilized the Prais-Winsten and Cochrane-Orcutt regression estimation process instead of opting for more complex time series regression estimation procedures such as hybrid auto-regressive moving average (ARMAX) models.

The third and final assumption addressed prior to specification involved estimates of variance used to produce confidence intervals and significance tests. Frequently, time series data exhibit error terms deemed to be heteroskedastic or produced by a non-Gaussian process which can inflate standard errors and thus bias coefficient estimates. We addressed these concerns through the use of the commonly used robust variance estimator (StataCorp 2009d).

Qualitative Data Collection and Analysis A total of 18 semi-structured interviews were completed with local residents within the three study communities. Local residents heavily involved in community affairs were the study's primary targets; these individuals included:

- elected officials $(n=5)$;

- civic leaders $(n=3)$;

- religious leaders $(n=2)$;

- business leaders (i.e., members of chambers of commerce or local tourism development boards) $(n=6)$; and

- other long-time residents who were referred to the interviewer $(n=2)$.

The majority of interviewees were male $(n=14)$ and all indicated being highly active in community-wide activities or local civic groups. Interviewees ranged from 45 to 72 years old and the average length of residence within their current community was 28 years. The lead author conducted all interviews. The interviews lasted between 20 and 60 minutes and were tape-recorded with the consent of each interviewee. Recordings were later transcribed verbatim.

The semi-structured interview questions were open-ended and concerned four primary topical areas: i) respondents' perceptions of their community's dependence upon natural resources and natural resource-based industries, ii) respondents' beliefs about the strength of existing social ties within their community, iii) respondents' perceptions of the biggest issues currently facing their community, and iv) respondents' beliefs about their community's ability to respond or adapt to changes brought about by those issues. Data analysis was an iterative process involving the identification of major themes and relationships between respondents' beliefs about resource dependence, existing stocks of social capital, and their community's past and future capability of mitigating or adapting to changing economic or environmental conditions. Major themes within the interview data were identified through an open coding process; subsequent relationships across and between major themes were identified through a comparative axial coding process (Corbin and Strauss 2007). Major themes represent relatively comprehensive expressions of social resilience from respondents within each community; subsequent relationships represent connections between the four topical areas elicited by the semi-structured interview script. Below, results from the analysis of qualitative data are presented for each community individually; the purpose being to describe relatively distinct processes of social resilience.

\section{Results}

Haywood County, North Carolina

Secondary Data Analysis Median household incomes within Haywood County have increased steadily over the past several decades (Fig. 2, Panel A, black line). In 1969, median household incomes were $\$ 7,189$, increasing to $\$ 39,042$ for 
2007. Income growth has been relatively consistent with no periods of prolonged stagnation or decline. However, Haywood County, like many other forest-associated communities in Southern Appalachia has become less and less reliant on natural resource based extraction industries (Fig. 2, Panel A, bar chart). In 1969 , nearly $10 \%$ of the county's total employment was in either farming, forestry, fishing, hunting or mining; a proportion that dropped to below $3 \%$ by 2007 . Another concomitant trend to the growth in median household incomes and the decline of natural resource based employment has been a steady expansion of the number of voluntary membership organizations within the county (Fig. 2, Panel
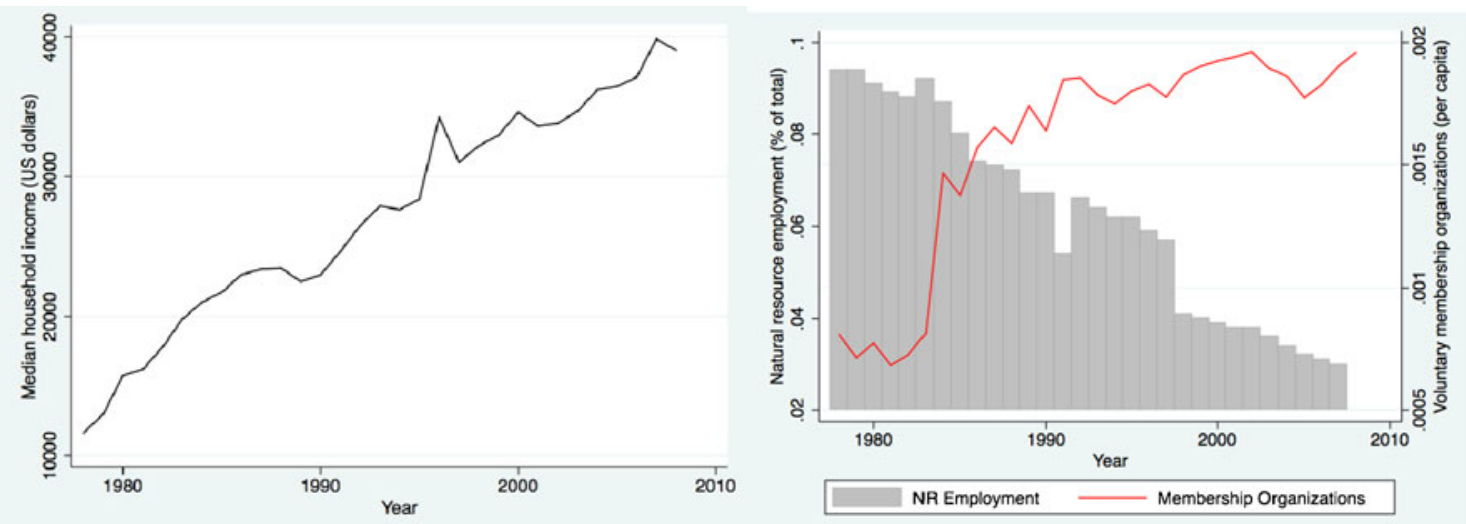

\section{A. Haywood County, North Carolina}
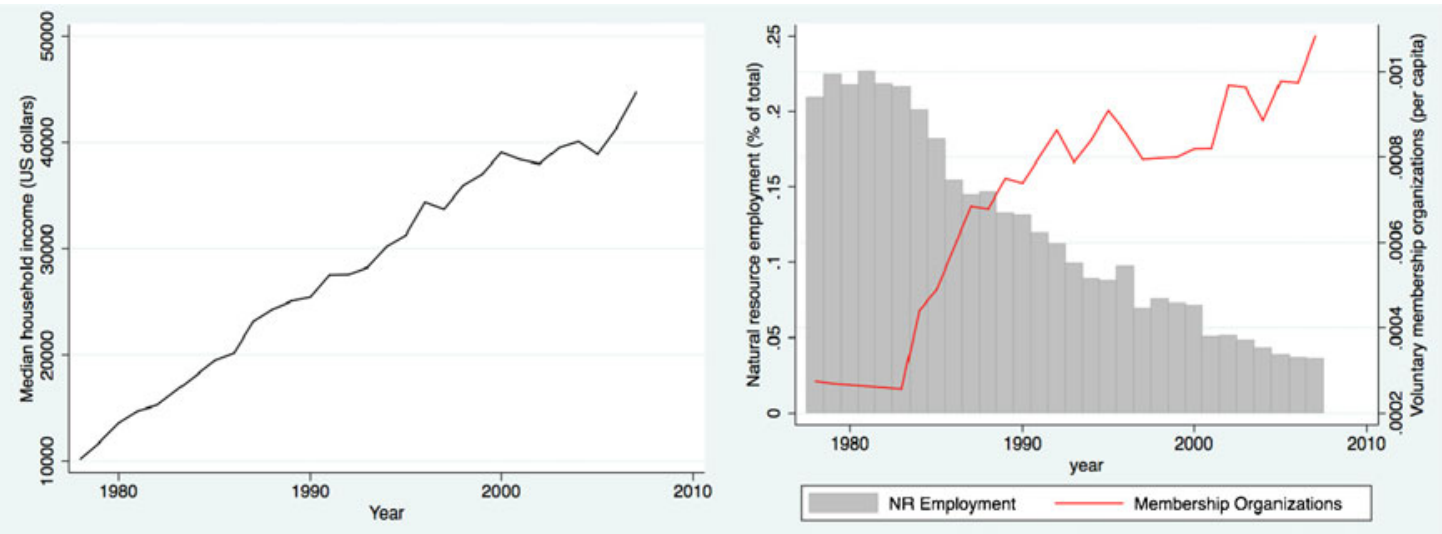

\section{B. Macon County, North Carolina}
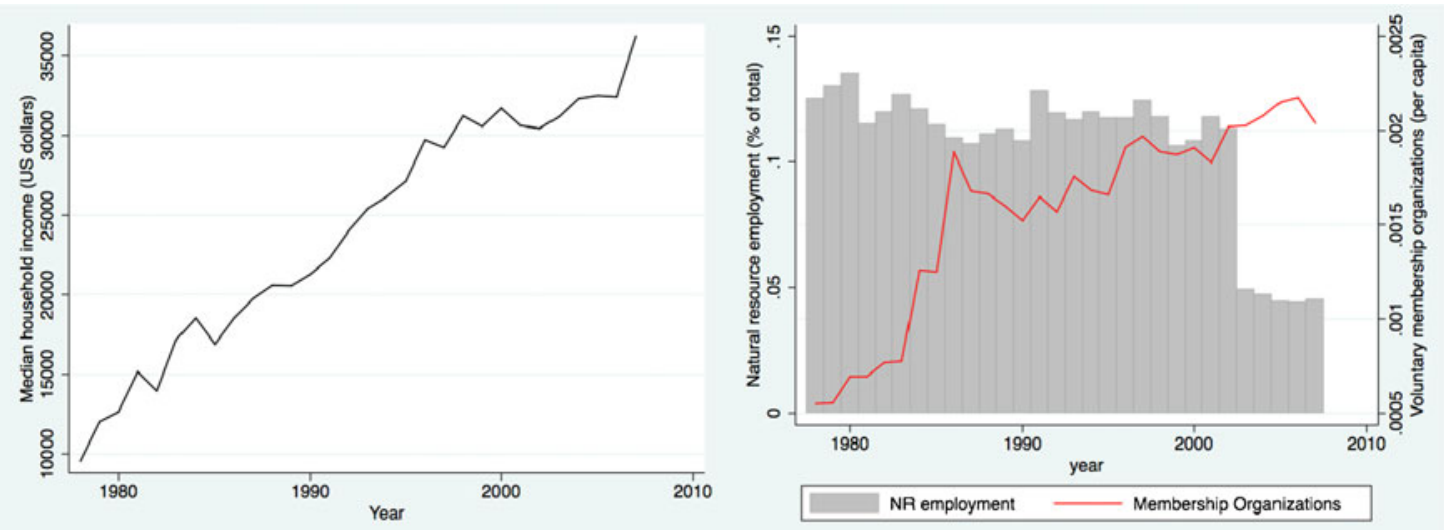

\section{Mitchell County, North Carolina}

Fig. 2 Median household income levels, natural resource-based employment, and per-capita voluntary membership organizations within Haywood, Macon and Mitchell Counties from 1977 to 2007 
A, red line). There were 37 volunteer membership organizations within the county in 1977, the first year data are available; by 2007 that number had increased to 107 . Even after controlling for population growth, the increase of non-market social institutions is notable. These descriptive data suggest Haywood County has been able to remain relatively economically stable over the past four decades. Given the decline in natural resource dependence and the increased number of voluntary membership organizations within the county, the stability of the economic growth appears to be less a product of resource dependence and more a product of increased stocks of social capital. To examine this hypothesis further, we utilize more inferential multivariate time-series statistics.

The initial augmented Dickey-Fuller test on detrended data revealed the median household income data for Haywood County to likely be generated by a stationary process. The interpolated critical value, $c$, at the 0.01 significance level was -3.709 and our test statistic, $t_{\hat{\theta}}$, was -1.414 . Given $t_{\hat{\theta}}>c$, the data provide strong evidence against the presence of a unit root and, alternatively, can be assumed to be generated by a stationary process. Given this, we calculated the autocorrelation across years and determined 1 lag to be appropriate in our subsequent autoregressive estimation.

The results from the regression model for Haywood County are presented in Table 1. Results concur with initial analysis of the descriptive data. Dependence upon natural resource employment had a significant and negative influence on the stability of median household incomes $(t=-9.33, p \leq 0.001)$. Conversely, the social capital measure, voluntary membership organizations per capita, had a significant and positive influence on the stability of median household incomes $(t=3.93$, $p \leq 0.001)$. The autocorrelation parameter, $\rho$, indicates the data are persistent, with strong evidence they are generated by a stable AR(1) process. The Durbin-Watson statistic is well below the critical value of 1.36 (Harvey 1989) which indicates the disturbances are serially correlated; the statistic also provides support for the use of the Prais-Winsten and CochraneOrcutt estimation procedure.

Qualitative Data Analysis The major social resilience theme identified by interviewees familiar with the history and social organization of Haywood County was autonomy and identity. Within each of the four topical areas queried about (resource dependence, existing stocks of social capital, current threats, adaptive capacities), respondents repeatedly referenced their community's strong desire to i) be able to control the economic and environmental conditions of their community, and ii) develop a unique identity that differentiated themselves from other similar areas within the region.

A large portion of Haywood County is public forest land under federal management through the USDA Forest Service. This fact provides the most striking evidence for the community's desire to remain a sense of economic and environmental independence. One respondent noted:

Our history with the Forest Service and with the [private] forest industry has been rocky in the past. Sometimes, we feel they've been too concerned with other areas in the region to give Haywood County a lot of attention. And none of us would like to see a big presence by the forest industry here...it kind of detracts from the kind of place that we are.

Further, and more substantial, evidence for expressions of autonomy and identity guiding the process of social resilience is evidenced by the county's major population center, Waynesville, purchasing through the administration of public bonds, an entire watershed immediately adjacent

Table 1 Results from Prais-Winsten and Cochrane-Orcutt regressions (1977-2007)

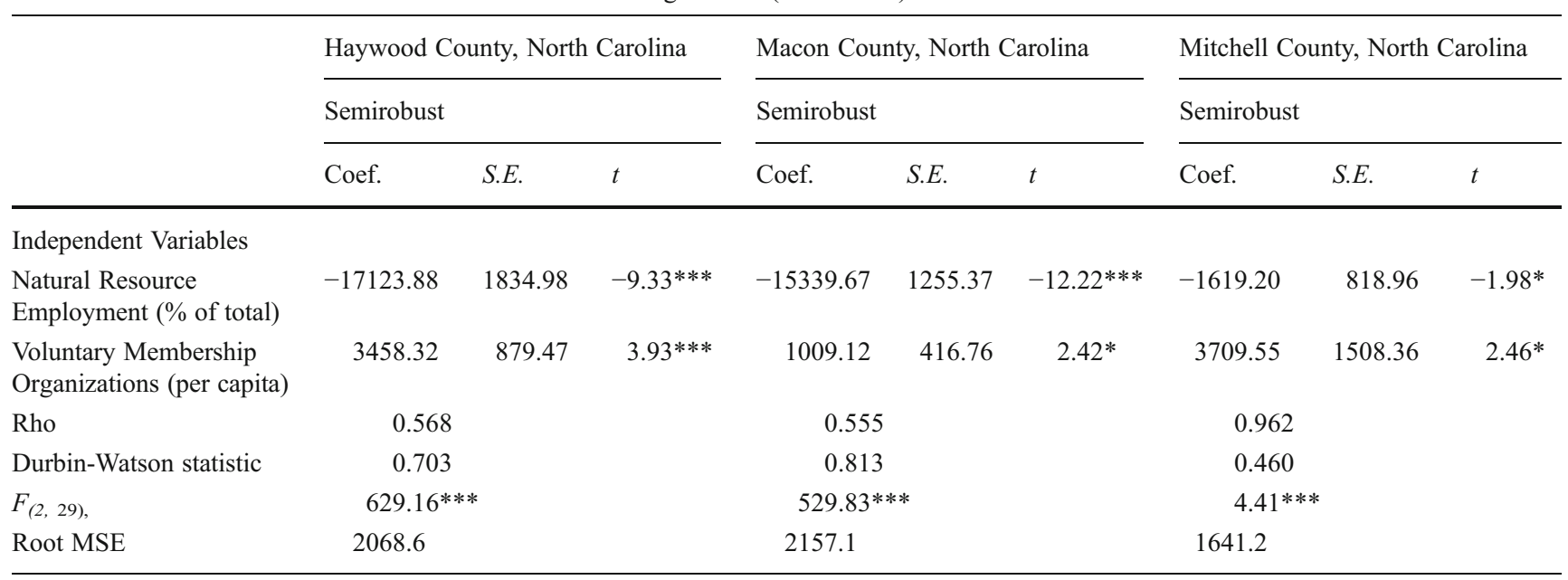

$* * * p \leq .001 ; * * p \leq .01 ; * p \leq .05$ 
to the city. The watershed, previously owned by private residents, provides much of the community's water supply. The public watershed was placed under an active forest management scheme designed to provide multiple benefits to the community. Limited timber harvesting is carried out and produces revenues which return to the city. Recreational activity is also limited to specific times and areas but, more importantly, provides local officials with control over a forest-based recreational resource not managed by the federal government or private interests. One respondent discussed the public watershed by saying:

We really feel that Waynesville has a unique sense of place, with the [Great Smoky Mountain] National Park located just up the road and the strong character of our downtown area. We know there are a lot of economic changes going on right now, most of which are out of our control. We're just trying to protect what we can and keep this place the same for our kids and their kids.

Other interviewees responded similarly regarding their community's desire to maintain a unique identity. A local business leader remarked:

Just walk up and down the streets here and you'll see how dependent we are on the environment. I mean, look at all the art galleries we have downtown. Almost all of them sell nature paintings or stuff related to the Smokies. That's why people come here and that's what we have to maintain. If this place looks like just like any other place why are people going to come? What's so unique about Waynesville?

Social resilience to economic and environmental stressors exhibited through comments related to autonomy and identity were key for interviewees in Haywood County. Perhaps partially guided by these or similar feelings, one city within the county actually exhibited, through public choice, the purchase of a local watershed for the purposes of preserving, to some degree, economic autonomy and the ability to actively manage a local natural resource while simultaneously maintaining their preferred image and identity within the region.

\section{Macon County, North Carolina}

Secondary Data Analysis Descriptive statistics for Macon County indicated similar trends to those found for Haywood County. Specifically, there has been a stable growth in median household income levels from 1969 (\$5,837) to 2007 (\$44,683) (Fig. 2, Panel B, black line). Macon County has also seen a consistent decline in the proportion of total employment in natural resource based industries (Fig. 2, Panel B, bar chart). Nearly $36 \%$ of the county's employment was in either farming, forestry, fishing, hunting or mining in 1969 , a proportion that dropped to $3.6 \%$ by 2007 . Similar to
Haywood County, the per-capita number of non-market volunteer organizations has risen dramatically since the early 1980s (Fig. 2, Panel B, red line). From 1977 to 1983 there were only 8 organizations within the county, by 2007 that number had increased nearly 8 -fold to 62 . Again, these data suggest a high level of economic stability despite dramatic changes in the county's natural resource based industries as well as evidence for the concomitant rise in aggregate stocks of social capital over the past 40 years.

Similar to results from Haywood County, the DickeyFuller test for the presence of a unit root on the detrended income data from Macon County revealed the likely presence of stationarity at the 0.01 level $\left(c=-3.716, t_{\hat{\theta}}=-0.649\right)$ and support for the inclusion of 1 lagged parameter in subsequent time-series analysis. The results from the regression estimation are presented in Table 1 and concur with the findings from Haywood County. Natural resource dependence had a significant and negative influence on income stability $(t=-12.22, p \leq 0.001)$. Our measure for social capital, on the other hand, was significantly and positively related to income stability $(t=2.42, p \leq 0.05)$. The data exhibited a notable amount of autocorrelation supporting the presence of a stable AR(1) process. Serial correlation among the disturbance parameters was also revealed by the Durbin-Watson statistic being less than the critical value of 1.36 .

Qualitative Data Analysis The major social resilience theme identified by interviewees involved in community affairs and civic organizations of Macon County was cross-scale linkages. For each of the topical areas discussed during interviews, interviewees frequently mentioned their community's strong ties to federal forest management or state resource management expertise as well as grants and resources made available to them as a result of these ties.

Similar to Haywood County, a large portion of Macon County is public forest under federal management through the USDA Forest Service. However, respondents living within Macon County did not mention the desire for local communities to detach themselves from federal management agencies, which was expressed by interviewees within Haywood County. Alternatively, interviewees within Macon County described their attachment, or dependence, upon federal forest management as a positive benefit that enabled the county to be more prepared for future economic and environmental changes. When asked about his community's ability to respond to changing environmental conditions, one respondent described his community's ability to draw upon their strong ties to the federal government:

The Forest Service has a long history in this area. I mean, the headquarters of the Nantahala [the National Forest which comprises much of Macon County] are located right here in Franklin (Macon County's most 
populous city). And their primary objective is to protect their interests in the forests, right? We have that as a distinct advantage when it comes to being able to address issues like climate change or beetle infestations or fires or whatever. They have all these resources committed to protecting the forests in which we live. If the city doesn't have to use tax revenues to pay for those protections, then I see that as a big plus.

Other interviewees described their community's connection to external sources of information and finances as a key factor enabling their community to adapt to changing environmental conditions. For example, one interviewee had been involved in the development of a county-wide farmland protection and agricultural development plan and expressed the benefits of cross-scale linkages by noting:

That plan was funded by a state-wide trust fund [the North Carolina Agricultural Development and Farmland Preservation Trust Fund]. The fund worked through the local ag[ricultural] extension office here in town to enable us to use the expertise of university scientists and researchers to develop a plan for more sustainable farming in the area. This is Franklin, I mean we only have like ten-thousand people living here. Having that kind of resource [access to external] expertise is a big help for us.

In summary, interviewees in Macon County predominantly discussed social resilience to changing economic and environmental conditions through their community's strong ties to external resources at both the federal and state levels. This theme of cross-scale linkages illustrates the benefits of greater stocks of social capital within the socio-economic linkages that can tie local communities to state and federal economies and organizations. Relying on the benefits of cross-scale linkages also provides a contrast to responses elicited by interviewees in Haywood County, where the process of resilience was described as one that needed to be guided much more by local control over economic and environmental conditions.

\section{Mitchell County, North Carolina}

Secondary Data Analysis For the most part, the descriptive results for Mitchell County mirror those seen in both Haywood and Macon counties. Median household income levels have grown steadily, from $\$ 5,307$ in 1969 to $\$ 36,239$ in 2007 (Fig. 2, Panel C, black line). The proportion of the county's total employment within natural resource based industries has dropped from a high of $13.5 \%$ in 1980 to below $5 \%$ in 2007 (Fig. 2, Panel C, bar chart). Concurrently, the number of non-market voluntary association groups have risen from 8 between 1977 and 1980 to 32 in 2007 (Fig. 2, Panel C, red line).
As with results from both Haywood and Macon Counties, the detrended median household income data provided strong evidence against the presence of a unit root $(c=-3.716$, $\left.t_{\hat{\theta}}=-0.936\right)$ and supported the inclusion of a single lagged parameter in subsequent analyses. Results from the regression estimation (Table 1) suggest, consistent with results from both Haywood and Macon counties, that greater levels of economic dependence upon natural resource based industries is significantly and negatively related to income stability $(t=-1.98, p \leq 0.05)$. The analysis also reveal a positive association between aggregate stocks of social capital and income stability $(t=2.46, p \leq 0.05)$. Also, the data were generated through a stable $\operatorname{AR}(1)$ process as evidenced by the high autocorrelation parameter, $\rho$. Finally, support for the use of the Prais-Winsten and Cochrane-Orcutt regression was given by the Durbin-Watson statistic falling below the critical value of 1.36 .

Qualitative Data Analysis The major social resilience theme identified by interviewees in Mitchell County was transitioning through tourism. In the four topical areas discussed, interviewees consistently identified the need to adapt to changing economic and environmental conditions by capitalizing on their community's heavy dependence upon the services sector. Mitchell county has the smallest population of the three communities examined; the county's primary population center of Spruce Pine only had an estimated 1,954 full-time residents in 2009 (U.S. Census Bureau 2011). The majority of the communties within the county were established as mining towns and have since transitioned into being primarily dependent upon regional travel and tourism. When asked about the largest economic and environmental issues facing their communities, interviewees in Mitchell provided detailed responses which framed current and future challenges as unique opportunities for development. For example, one interviewee noted:

I've seen some of the university scientists' predictions about how climate change will affect the area, and it seems to me that Southern Appalachia is one of the few areas that could actually benefit from warmer climates. Were not like the coast who has to deal with sea level rise or eroding beaches... what it means for us is a longer tourism season. Most of our visitation comes in the summer because its cooler up in the mountains than down in Winston-Salem or Raleigh. That's when a lot of people come up here, so I see it as a benefit for the area.

Other respondents, particularly those associated with local business interests, suggested similar beliefs. Several, for example, described how their community would adapt easily because future environmental conditions produced more benefits than costs. 
Several of the respondents within Mitchell County, many of the same ones who believe changing environmental conditions will benefit them, also realized there were reciprocal and sometimes negative effects associated with future community change. One respondent described these feelings well by noting:

We've always had a lot of interest in [private business interests] wanting to get more people up here. And I guess a lot of that is inevitable with population growth and everything...but that's not why most of us live here. The forests are a critical part of our community; they should be managed for their own intrinsic value and not for tourism.

While not all respondents in Mitchell County specifically discussed climate change as a major economic or environmental issue facing their community, all discussions did involve the connection between tourism and economic health. The relationships between the area's dependence upon natural resources and its concomitant effect on the health of local economies were almost always discussed through dichotomous illustrations where benefits in one arena always came at the expense of costs in the other. One interviewee summed this up by noting, "We're going to have to adapt and the community is going to change. But whether or not we like what we change into is a different story."

\section{Discussion}

We began this research with two primary objectives: i) to determine the relationship between natural resource dependence and long-term social stability; and ii) to describe resilience as a process facilitated through the presence of specific types and patterns of social interaction. To achieve these objectives, we utilized a mixed method multiple case study methodology looking specifically at three counties located within the southern Appalachian Mountains. The methodological approach enabled us to collect data that were temporally and conceptually broad as well as theoretically deep. This approach also allowed us to directly examine the social processes of resilience, an important area of research that is often limited by traditional methodological approaches (Tschakert and Dietrich 2010).

With regard to our first objective, time-series data from each of the three study communities supported the hypothesis that natural resource dependence has a significant and negative effect on socio-economic stability. For natural resource social scientists, this finding is not surprising as previous research has firmly established that greater levels of economic dependence upon natural resource based industries leads to negative social outcomes such as increased poverty rates (Fisher 2001; Nord 1994; Freudenburg 1992), crime rates (Force et al. 1993), and unemployment rates (Stedman et al. 2004; 2005). This finding, consistent with previous studies examining the forest industry in Canada (Parkins et al. 2003), begs the question of whether or not other social factors, such as greater levels of social interaction, can assuage these negative effects and perhaps lead to an increased level of social stability in resource dependent communities. Through the inclusion of aggregate social capital along with our analysis of the time-series data, we found support for this hypothesis within each of our three cases. Just as consistently as increased levels of resource dependence reduced the social stability of each case, the data suggested that social capital had the opposite effect.

For natural resource social scientists and community organizers, knowing that greater levels of social capital can provide a boon to adaptive capacities of resource dependent communities is useful. However, the full utility of this finding cannot be realized without an appreciation of how specific patterns of social interaction (e.g., the distinct forms of social capital) actually influence the ability of communities to adapt to changing conditions. The qualitative data from each of our case studies illustrate three distinct ways, likely among many, that community resilience can be expressed through distinct patterns of social interaction.

Interviewees in Haywood County, by describing their community's desire to respond to external threats by obtaining more control over their local economy and environment, expressed a pattern of high bonding - high bridging ties with apparently little desire for cross-scale connectivity. Interviewees in Macon County, however, expressed their resilience to major community threats in a dramatically different way. Interviewees in Macon County frequently mentioned their community's connections to either state or federal agencies and institutions which could be leveraged to gain access to financing or other resources needed to meet current and future challenges. The interview data, characterized by the major theme of cross-scale linkages describes a distinct pattern of social interaction characterized by low bonding - high bridging ties with a strong desire for crossscale connectivity. Finally, interviewees in Mitchell County described community resilience with a considerable amount of reluctance. Interviewees were aware of the growing demand for tourism and that global change forces would likely hasten and intensify those demands. However, the ambivalence and reluctance in the interview data also revealed a notable degree of within-community factionalism over whether the changes brought about by increased tourism would actually be a good thing for the local population. Again, the data suggest a distinct form of social interaction characterized by high bonding - low bridging ties with mixed desires for increased cross-scale connectivity. 
Our analysis of time-series data for each of the three counties suggests social capital plays an integral role in social resilience. However, the aggregate level of the data obscures the process of social resilience. Social interaction does appear to have an influence on resilience, but how does that interaction actually manifest itself? The logic behind our replicated multiple case study design attempted to address this issue by determining if community leaders from three very similar counties all described their community's ability to adapt to external stressors in similar ways. The findings revealed multiple resilience pathways (Fig. 1, Panel B), each defined by specific combinations of community ties. In short, the data suggest the social process of resilience is not deterministic, being carried out by community leaders investing in a specific type of social capital. Rather, community investment in specific types of social capital are likely to have more of an influence on how a community adapts and responds to changing environmental conditions more so than if that community will adapt and respond at all.

Acknowledgements This research was supported by a doctoral dissertation improvement grant from the National Science Foundation (Award No. 1030395) and a Hoffmann Fellowship from the College of Natural Resources at North Carolina State University. The authors would like to thank Dr. Ed Kick, Dr. Hugh Devine, and Hollie Smith for their comments and suggestions.

\section{References}

Adger, W. N. (2000). Social and Ecological Resilience: Are They Related? Progress in Human Geography 24: 347-364.

Adger, W. N. (2003). Social Capital, Collective Action, and Adaptation to Climate Change. Economic Geography 79: 387-404.

Aspinall, R. (2010). Geographical Perspectives on Climate Change. Annals of the Association of American Geographers 100: 715719 doi:10.1080/00045608.2010.502408.

Bourdieu, P. (1986). The Forms of Capital. In Richardson, J. G. (ed.), Handbook of Theory and Research for the Sociology of Education. Greenwood Press, New York, pp. 241-258.

Box, G. E. P., Jenkins, G. M., and Reinsel, G. C. (1994). Time Series Analysis: Forecasting and Control, 3rd ed. Prentice Hall, Englewood Cliffs, NJ.

Brown, R. B., Dorins, S. F., and Krannich, R. S. (2005). The BoomBust-Recovery Cycle: Dynamics of Change in Community Satisfaction and Social Integration in Delta, Utah. Rural Sociology 70: 28-49 doi:10.1526/0036011053294673.

Castells, M. (1977). The Urban Question: A Marxist Approach. MIT Press, Cambridge, MA.

Coleman, J. S. (1988). Social Capital in the Creation of Human Capital. American Journal of Sociology 94: S95-S120.

Coleman, J. S. (1990). The Foundations of Social Theory. Harvard University Press, Cambridge, MA.

Corbin, J. M., and Strauss, A. C. (2007). Basics of Qualitative Research: Techniques and Procedures for Developing Grounded Theory, 3rd ed. Sage Publications, Thousand Oaks, CA.

Davidson, D. J. (2010). The Applicability of the Concept of Resilience to Social Systems: Some Sources of Optimism and Nagging Doubts.
Society \& Natural Resources 23: 1135-1149 doi:10.1080/ 08941921003652940

Davidson, R., and MacKinnon, J. G. (1993). Estimation and Inference in Econometrics. Oxford University Press, New York.

Dey, I. (1999). Grounding Grounded Theory: Guidelines for Qualitative Inquiry. Academic, San Diego, CA.

Dickey, D. A., and Fuller, W. A. (1979). Distributions of the Estimators for Autoregressive Time Series with a Unit Root. Journal of the American Statistical Association 74: 427-431.

Durkheim, E. (1933). The Division of Labor in Society. Free Press, Glencoe, IL.

Elliott, G., Rothenberg, T. J., and Stock, J. H. (1996). Efficient Tests for an Autoregressive Unit Root. Econometrica 64: 813-836.

Field, D. R., Luloff, A. E., and Krannich, R. S. (2002). Revisiting the Origins of and Distinctions Between Natural Resource Sociology and Environmental Sociology. Society \& Natural Resources 15: 213-227 doi: $10.1080 / 089419202753445052$.

Fisher, J. (2001). Resource Dependency and Rural Poverty: Rural Areas in the United States and Japan. Rural Sociology 66: 181202.

Flora, C.B., and Flora, J.L. (2003). Social Capital. In Challenges for Rural America in the Twenty-First Century, The Pennsylvania State University Press, State College, PA. pp. 214-227.

Folke, C., Carpenter, S., Elmqvist, T., Gunderson, L., Holling, C. S., and Walker, B. (2002). Resilience and Sustainable Development: Building Adaptive Capacity in a World of Transformations. AMBIO: A Journal of the Human Environment 31: 437-440 doi:10.1579/0044-7447-31.5.437.

Folke, C., Hahn, T., Olsson, P., and Norberg, J. (2005). Adaptive Governance of Social-Ecological Systems. Annual Review of Environment and Resources 30: 441-473 doi:10.1146/annurev. energy.30.050504.144511.

Force, J. E., Machlis, G. E., Zhang, L., and Kearney, A. (1993). The Relationship Between Timber Production, Local Historical Events, and Community Social Change. Forest Science 39: 722-742.

Freudenburg, W. R. (1992). Addictive Economies: Extractive Industries and Vulnerable Localities in a Changing World Economy. Rural Sociology 57: 305-332.

Freudenburg, W. R., and Gramling, R. (1994). Natural Resources and Rural Poverty: A Closer Look. Society \& Natural Resources 7: 5-22.

Gittell, R., and Vidal, A. (1988). Community Organizing: Building Social Capital as a Development Strategy. Sage, Thousand Oaks, CA.

Gomm, R., Hammersley, M., and Foster, P. (2000). Case Study Method: Key Issues, Key Texts. Sage, Thousand Oaks, CA.

Granovetter, M. S. (1973). The Strength of Weak Ties. The American Journal of Sociology 78: 1360-1380.

Hamilton, J. D. (1994). Time Series Analysis. Princeton University Press, Princeton, NJ.

Harvey, A. C. (1989). Forecasting, Structural Time Series Models and the Kalman Filter. Cambridge University Press, Cambridge, United Kingdom.

Hawley, A. H. (1950). Human Ecology: A Theory of Community Structure. Ronald Press, New York.

Herriott, R. E., and Firestone, W. A. (1983). Multisite Qualitative Policy Research: Optimizing Description and Generalizabilty. Educational Researcher 12: 14-19.

Holling, C. S. (1973). Resilience and Stability of Ecological Systems. Annual Review of Ecology and Systematics 4: 1-23.

Holling, C. S., and Gunderson, L. H. (2002). Resilience and Adaptive Cycles. In Gunderson, L. H., and Holling, C. S. (eds.), Panarchy: Understanding Transformations in Human and Natural Systems. Island Press, Washington, DC, pp. 25-62.

Machlis, G. E., and Force, J. E. (1988). Community Stability and Timber-Dependent Communities. Rural Sociology 53: 220-234.

May, R. M. (1977). Thresholds and Breakpoints in Ecosystems with a Multiplicity of Stable States. Nature 269: 471-477. 
McIntosh, R. J., Tainter, J. A., and McIntosh, S. K. (2000). The Way the Wind Blows: Climate, History, and Human Action. Columbia University Press, New York.

National Research Council (2010a). America's Climate Choices: Adapting to the Impacts of Climate Change. National Research Council, Washington, DC.

National Research Council (2010b). America's Climate Choices: Advancing the Science of Climate Change. National Research Council, Washington, DC.

Nord, M. (1994). Natural Resources and Persistent Rural Poverty: In Search of the Nexus. Society \& Natural Resources 7: 205-220.

Parkins, J. R., Stedman, R. C., and Beckley, T. M. (2003). Forest Sector Dependence and Community Well-Being: A Structural Equation Model for New Brunswick and British Columbia. Rural Sociology 68: 554-572.

Robison, L. J., and Siles, M. E. (1999). Social Capital and Household Income Distributions in the United States: 1980, 1990. Journal of Socio-Economics 28: 43-93.

Rupasingha, A., Goetz, S. J., and Freshwater, D. (2002). Social and Institutional Factors as Determinants of Economic Growth: Evidence from the United States Counties. Papers in Regional Science 81: 139-155.

Rupasingha, A., Goetz, S. J., and Freshwater, D. (2006). The Production of Social Capital in U.S. Counties. Journal of SocioEconomics 35: 83-101 doi:10.1016/j.socec.2005.11.001.

Schulman, M. D., and Anderson, C. (1999). The Dark Side of the Force: A Case Study of Restructuring and Social Capital. Rural Sociology 64: 351-372.

Smith, M. D., Krannich, R. S., and Hunter, L. M. (2001). Growth, Decline, Stability, and Disruption: A Longitudinal Analysis of Social Well-Being in Four Western Rural Communities. Rural Sociology 66: 425-450 doi:10.1111/j.1549-0831.2001.tb00075.x.

StataCorp. (2009a). [d] data management, ipolate. In Stata: Release 11, StataCorp LP, College Station, TX, pp. 339-340.

StataCorp. (2009b). [ts] time-series, dfgls. In Stata: Release 11, StataCorp LP, College Station, TX, pp. 111-116.
StataCorp. (2009c). [ts] time-series, corrgram. In Stata: Release 11, StataCorp LP, College Station, TX, pp. 77-83.

StataCorp. (2009d). [r] base reference, vce option. In Stata: Release 11, StataCorp LP, College Station, TX, pp. 2010-2014.

Stedman, R., Parkins, C. J., and Beckley, T. (2004). Resource Dependence and Community Well Being in Rural Canada. Rural Sociology 69: 213-234.

Stedman, R., Parkins, C. J., and Beckley, T. (2005). Forest Reliance and Community Well Being in Rural Canada: Variations by Forest Sector and Region. Canadian Journal of Forest Resources 35: 215-220.

Stedman, R., White, W., Patriquin, M., and Watson, D. (2007). Measuring Community Forest-Sector Dependence: Does Method Matter? Society \& Natural Resources 20: 629-646 doi:10.1080/ 08941920701329660.

Tschakert, P., and Dietrich, K. A. (2010). Anticipatory Learning for Climate Change Adaptation and Resilience. Ecology and Society 15: 11.

U.S. Census Bureau. (2011). Spruce Pine town, North Carolina Population Finder - American FactFinder. U.S. Census Bureau American FactFinder. http://factfinder.census.gov/servlet/ SAFFPopulation?_event $=$ Search\&_name $=$ Spruce + Pine \& state $=04000$ US37\&_county $=$ Spruce + Pine $\&$ cityTown $=$ Spruce + Pine \& $z i p=\&$ sse $=$ on \& lang $=$ en $\& p c t x t=f p h$.

Wilbanks, T. J., and Kates, R. W. (2010). Beyond Adapting to Climate Change: Embedding Adaptation in Response to Multiple Threats and Stresses. Annals of the Association of American Geographers 100: 719-728 doi:10.1080/00045608.2010.500200.

Wilkinson, K. P. (1999). The Community in Rural America. Social Ecology Press, Middleton, WI.

Woolcock, M. (1998). Social Capital and Economic Development: Toward a Theoretical Synthesis and Policy Framework. Theory and Society 27: 151-208.

Wooldridge, J. M. (2008). Introductory Econometrics: A Modern Approach, 4th ed. South-Western College Publishers, Australia.

Yin, R. K. (2009). Case Study Research: Design and Methods, 4th ed. Sage, Los Angeles. 